\title{
A Corporate Beauty Contest
}

John R. Graham, Campbell R. Harvey and Manju Puri

Fuqua School of Business, Duke University, Durham, NC 27708, USA

National Bureau of Economic Research, Cambridge, MA 02912, USA

March 2010

\begin{abstract}
We conduct beauty contest experiments, using close to 2,000 subjects to study the facial traits of CEOs. In one experiment we use pairs of photographs and find that subjects rate CEO faces as appearing more "competent" and less "likable" than non-CEO faces. Another experiment matches CEOs from large firms against CEOs from smaller firms and finds large-firm CEOs look more competent and likable. In a third experiment, subjects numerically rate the facial traits of CEOs. We find that executive compensation is linked to these perceived "competence" ratings. Our analysis explores these findings in more detail and shows that the facial-trait rating can be explained by a quantitative scoring of the "maturity" or "baby-facedness" of the CEO. That is, more mature looking CEOs are assigned higher "competence" scores. This finding is potentially worrisome because psychology research shows that baby-faced-looking people often possess qualities opposite to those projected by their facial traits. Accordingly, we find no evidence that the firms of competent looking CEOs perform better. Essentially, the "look" of competence says very little about effective competence.
\end{abstract}




\section{Introduction}

A provocative theme in economics research suggests there is a "beauty premium" in which workers of above-average beauty earn more than workers with below average looks (see e.g., Hamermesh and Biddle, 1994). ${ }^{1}$ These results suggest that perception based on facial attributes is important. However, there is relatively little research in economics or corporate finance examining the broader impact of facial traits beyond beauty, though there is a large psychology literature that examines facial traits more generally. As an intriguing example of the latter, Todorov et al. (2005) find that winners in congressional elections can be predicted by appearance. In this experiment, study participants are exposed to the faces of a pair of politicians with whom they are not familiar for as little as one second. Surprisingly, the inference drawn in a blink of an eye about which politician looks more competent was a good predictor of the outcomes of U.S. congressional elections.

The question of whether and how looks matter, and in particular, whether facial traits are relevant is especially interesting in the corporate context. The decision as to who runs companies and the appointment of a CEO is often a heavily contested process. This situation differs from that of politicians insofar as there is not only a long track record available on chief executive candidates and the eventual winner, but the decision as to who is appointed CEO is likely made by a handful of people intimately familiar with the track record of the CEO candidates. In such situations, where there is ample information about past record and performance, and the decision is made by a handful of informed people, do looks still matter?

\footnotetext{
${ }^{1}$ See also Biddle and Hamermesh (1998); Mobius and Rosenblat (2006).
} 
We address this question using a web-based experimental design in which we have about 2,000 participants evaluate facial attributes of the CEOs of companies with facial attributes of a control sample of the same gender, race, and similar age. We first do pair-wise comparisons of CEOs to a control sample. We ask respondents to assess the facial attributes of the CEO to a matched non-CEO counterpart on four dimensions: beauty, competence, trustworthiness, and likeability. We next compare CEOs of large firms with CEOs of small firms on the same four facial traits. We find two facial traits that consistently distinguish between CEOs and the control group: competence and likeability. Our results indicate that individuals who appear more competent and less likable are more likely to be CEOs. We similarly find these two traits are also significantly related to the CEO heading a larger company.

Our results on facial attributes are particularly striking given that there is no evidence in the literature that trait inferences from facial appearances are correlated with actual underlying characteristics. Indeed there is evidence that trait inferences can be wrong. For example, Collins and Zebrowitz, 1995, show that baby-faced individuals who are judged less competent than mature-faced individuals actually tend to be more intelligent. Indeed, research testing the model of appearance-trait relations has provided evidence that baby-faceness produces a self-defeating prophecy effect. In particular, baby-faced people often have traits opposite to those that perceivers expect, including assertiveness, hostility, and physical bravery (Collins \& Zebrowitz, 1995; Zebrowitz, 1997; Zebrowitz, Andreoletti, Collins, Lee, and Blumenthal, 1998). Similarly, Mobius 
and Rosenblatt, 2006, find that physically attractive workers are (wrongly) considered more able by employers.

Accordingly we investigate whether facial attributes are related to firm performance. We regress the return on assets of the firm run by the CEO on the facial attributes of competence, beauty, trustworthiness, and likability, after controlling for size of the company, industry and the return on assets obtained by the prior CEO. The facial traits are uniformly insignificant with point estimates near zero. These results are consistent with those suggested by the psychology literature that trait inferences from facial appearances can be misleading, i.e., having the appearance of a facial trait does not mean one will actually display that trait.

We also investigate whether these facial attributes are correlated with increased wages. Here we examine all the facial assessments of competence, beauty, trustworthiness, and likability, which we then tie to compensation using executive compensation data from S\&P's Execucomp database. We correlate the evaluations of beauty and competence with the wage earned by CEOs to assess whether there is a “competent looks” premium. We find that CEOs who are judged to be more competentlooking tend to also earn higher wages but no other facial trait is significant.

We then ask if the CEO relative pay is a function of facial attributes. We regress the CEO compensation on facial attributes to see if any of these are significant after controlling for the previous CEO's pay at that same firm, and controlling for company size and industry. We find competence is significant in these regressions but none of the 
other facial characteristic is significant. Our evidence supports the idea that in the market for CEOs there is a “competent looks” wage premium.

What leads to assessments of competence based on facial attributes? One branch of the psychology literature that examines the ecological basis for evaluation of facial attributes suggests that onlookers tend to assign characteristics of infants to adults with a baby-faced appearance. Thus, baby-faced individuals are generally perceived to have childlike traits and are positively correlated with perception of naïveté, honesty, kindness and warmth (see e.g., Berry and McArthur, 1985). In a recent study, Zebrowitz and Montepare (2005) suggest that differences in perception of competence also stems from visual differences in "baby-facedness." Accordingly, we additionally assess whether CEOs differ in terms of baby-facedness relative to a control group, and whether this is correlated with the perception of competence. We find this is indeed the case. CEOs are generally viewed as being more mature-faced as opposed to baby-faced than are nonCEOs, and this visual maturity is positively correlated with the perception of competence and negatively related to the perception of likeability.

Our results suggest a broader agenda for the influence of facial traits on job occupation and wages. ${ }^{2}$ We provide evidence that suggests that for corporate executives, especially CEOs, facial traits leading to the perception of competence seem important. Not only are such facial traits a dominant characteristic of CEOs, they also distinguish CEOs who run large companies from small companies. Our results suggest that it would

\footnotetext{
${ }^{2}$ Some recent work examines the influence of pictures in peer-to-peer lending. See e.g., Ravina, 2009; Duarte et al., 2009. Rule and Ambady, 2008, examine the appearance of power related executive traits.
} 
be useful to investigate a broader set of facial traits in different settings to investigate how they relate to occupation and earnings.

The paper is structured as follows. Section 2 describes the method and experiments that we employ. Section 3 describes our analysis and results. Section 4 offers our conclusions.

\section{Experiments}

\subsection{CEO matched pair experiment}

In this experiment we do a pair-wise comparison of photographs of CEOs with a control group of non-CEOs and have respondents compare the facial traits of the CEOnon-CEO pair in terms of competence, attractiveness, trustworthiness, and likeability. To conduct this experiment, we engaged in the following steps.

\section{A. Collecting the photographs of CEOs}

We obtained the initial list of CEOs from S\&P's Execucomp database for 2004. We stratified to collect a reasonable sample of photographs of the CEOs of large and small companies. For this purpose we did a stratified sample where we over sample from the largest and the smallest firms.

We then searched company websites for pictures of CEOs. Our goal was to make sure the photographs were standard. Standard features included: the resolution of the 
color photograph, business dress, bland background, and a conventional pose. The photos were cropped so that the head sizes were approximately the same.

B. Creating a matched CEO and non-CEO photograph pair experiment

For this experiment, photographs of the sample of CEOs were matched with photographs of a control group belonging to other occupations. To form the control group, we sought photographs of non-CEOs in business attire and similar professional pose as the CEO photographs. The photographs of the control group were matched to photographs from the CEO group using features such as similar hair (combed on side, bald, etc.), color of coat, glasses, facial hair, and facial expression (e.g., both individuals in the matched pair are smiling). Matching on these traits may work against onlookers being able to identify CEOs but focuses the experiment on facial characteristics. Ninety CEO's were chosen to match the control group pictures. In the end, we divided 87 pairs into roughly three groups of $29 .{ }^{3}$ Given that the subject only looks at about 30 pictures in the experiment, we only needed 44 control group pictures. ${ }^{4}$ That is, the control group photos could be used two or three times, but CEO photos were only used once in forming the 90 pairs. As with the first experiment, photographs were cropped so that the head sizes were comparable. Respondents were asked to sequentially examine a deck of 30 pairs and assess which person in each pair looked more competent, attractive, trustworthy and likable, respectively. Figure 1 gives an example screen shot of the first experiment as well as the initial screen that the subject sees.

\footnotetext{
${ }^{3}$ We were unable to find an adequate control photo for three of the 90 CEO photos which explains why the sample if 87 rather than 90.

${ }^{4}$ We needed more than 30 control group photos because we were matching based on amount of hair, glasses, etc.
} 


\section{Large company CEOs versus small company CEOs}

For this experiment, photographs of the CEO's from the 351 companies with the greatest sales revenue were considered large company CEOs, and CEO’s from companies ranked 352 to 1,753 (in sales) were placed into the small company group. The photos from the small company CEOs were matched to photographs of the big company CEOs based on the same criteria as the first experiment. Emphasis was placed on matching the largest of the large company group with the largest of the small company group in order to ensure as substantial a difference in size as possible between the two pairs. Sixty matched pairs were formed, and these 60 were divided into two groups of 30 . Respondents were asked to examine a deck of 30 pairs and assess which one of each pair looked more competent, attractive, trustworthy and likable, respectively. Figure 2 presents a screen shot of the second experiment.

\section{Design and delivery}

We created five decks of paired experiments (three for the assessment of facial attributes of CEOs versus a control group, and two for large company CEOs versus small company CEOs). The experiments were delivered on the Internet. Each respondent was randomly assigned one deck of 30 pairs. For each pair the respondent made an assessment as to which person in the pair looked more competent, attractive, trustworthy and likable. We did not limit the amount of time that a subject spent doing the experiment. 
Our respondents were generated by emails sent to both graduate and undergraduate students in business administration at Duke University and the University of North Carolina at Chapel Hill. ${ }^{5}$ The email asked them to forward our email to other business students at different institutions and to post our link on student-oriented blogs.

The experiment generated 1527 subjects.

\subsection{Additional Experiments}

As an additional experiment, we have a new group of subjects rank each of the four attributes (beauty, competence, likeability and trustworthiness) on a scale of 1-5. We have 138 CEO pictures from the initial step in the previous experiment. These were divided into two batches. Each subject was given a deck of about 70 CEOs to score, with the deck being randomly assigned. This process allowed us to create ratings on a scale of 1-5 for 138 CEOs for each of the four attributes. We emailed the same group of graduate and undergraduate students and generated 230 subjects. Since competence appears to be the most important attribute in our study and prior work suggests the importance of beauty, to ease the rating task and reduce the chance of visual burnout, we recruited an additional 208 subjects to only rank the CEO on competence and beauty on a scale of 15. An example of the ratings screen for this third experiment is presented in Figure 3.

\subsection{Baby-faced Ratings}

One branch of the psychology literature that attempts to evaluate why appearance affects social perception investigates whether an ecological approach to perception might

\footnotetext{
${ }^{5}$ The email to University of North Carolina students was sent from our nber.org email addresses to avoid any Duke / UNC rivalry effects and to maximize the response rate.
} 
help explain the link between facial features and specific personality impressions. Following this approach, a number of studies examine if a baby-faced appearance yields the impression of infantile psychological attributes. Berry and McArthur (1985) find that physical measurements of large, round eyes, high eyebrows and a small chin yielded the perception of a baby faced appearance. Baby-facedness ratings were positively correlated with perceptions of a person's naiveté, honesty, kindness and warmth. The implication is that baby-faced people are perceived as more trustworthy and less competent. We test for this effect by having the baby-facedness of the CEOs and control group assessed. We then correlate the baby-faced characteristic to evaluations of competence based on facial characteristics.

We ask a small number of 10 Duke University Ph.D. students to score the faces of the CEOs in terms of whether they are baby-faced or mature on a scale of 1-5. 138 CEOs are evaluated. We examine the correlation of baby-faced/maturity with the other traits. Consistent with the evidence in the prior literature, we find baby-faced individuals are perceived to be significantly less competent, and more likable. They are also viewed to be more trustworthy and attractive but these correlations are not significant.

\section{Results}

\section{A. Identifying CEOs based on facial traits}

Panel A of Table 1 provides results on the percentage of time that the subject chooses the CEO based on competence, trustworthiness, likeability and attractiveness. There are 87 CEO pairs and 765 subject responses. Key to our experiment, 54.13\% 
percent of the subjects identified the CEO when asked to choose which person they felt was more “competent”. We report both straight averages as well as observation weighted averages. The observation weighted average is $53.8 \%$. The straight average calculates the percentage of the time the CEO was picked for each pair and reports the mean of these pair averages. Observation weighted averages represent the percentage of all respondentpair observations for which the CEO was picked. We report t-tests whether the averages are significantly different from the null hypothesis of $50 \%$.

For each of the four traits, we find statistically significant differences. CEOs are viewed as more competent and more attractive. However, they are also viewed as less trustworthy and less likable. The sharpest difference is found in the perception of competence.

Panel B presents the same analysis for CEOs of large firms versus CEOs of small firms. There are 60 large-small firm CEO pairs and 762 subjects. There are many similarities in the results. Each of the four traits yields statistically significant results. For example, $54.48 \%$ of the respondents classify the large firm CEO as more competent than the small firm CEO. $44.45 \%$ of the subjects think that the large firm CEO is less likable than the small firm CEO. Similarly, the large firms CEOs are viewed as less trustworthy. Interestingly, the only major difference between the panel A experiment and the panel B experiment has to do with attractiveness. From panel A, we know that CEOs are more attractive than our control group. From panel B, small firms CEOs are perceived to be more attractive than large firm CEOs. 
What is the economic significance of our results compared to inferences of competence based on facial traits in other settings? Todorov et al. (2005) find that candidates perceived as more competent won in $71.6 \%$ of Senate races and in $66.8 \%$ of House races. In our experiment $54.13 \%$ of subjects identified the CEO as the person who was perceived as more competent. This is clearly smaller than the Todorov et al. (2005) study. In some ways this is reassuring. The decision to appoint CEOs is not done by the layman (voter) on the street. Rather CEO succession is often a hard and long deliberated process engaged in by the Board of Directors who are intimately familiar with the CEO track record and performance. The surprise is that "competent looks" matter in such decisions where there is a lot of information and the decision is made by a handful of people typically spending many months over the process.

\section{B. Scoring facial traits}

Table 1 presents evidence consistent with the hypothesis that facial traits appear to be important in discriminating between CEOs vs. non-CEOs as well as large and small firm CEOs. However, this type of experiment cannot be used to link traits to compensation. To do this, we need to numerically score the facial traits.

Table 2 shows a correlation matrix of the numerical scores assigned to the four attributes. In this experiment, 138 CEOs were rated. There are 230 subjects. In subsequent analysis we will focus on the link between facial traits and compensation. We perform this analysis only for CEOs as we have data on CEO compensation from S\&P Execucomp and no data on compensation for our control group of non-CEOs. As a precursor to this analysis we examine these four traits. Table 2 shows us that all four 
traits are positively correlated. The largest correlation is found between trustworthiness and likeability. The smallest correlation is between trustworthiness and attractiveness.

The analysis of facial traits and compensation is presented in Table 3. We examine log total income of the CEO (“TDC1" in Execucomp). ${ }^{6}$ Given the strong link documented between firm size and compensation (see e.g., Bebchuck and Grinstein, 2005) we also include a variable to control for company size: the natural logarithm of sales of the company for fiscal year 2003. When we encounter missing values, we use data for 2004 or 2005. We examine the correlation between compensation and the size measures on the numerical scores for the four traits. The standard errors are adjusted for clustering by CEO. There are 230 respondents.

The results in Table 3 show that perceived competence is positively related to compensation and likeability is negatively related to compensation. This is consistent with the experiment in Table 1 that showed that CEOs were perceived to be more competent and less likable than the control sample. It is also consistent with the results in Table 1 that shows that large firm CEOs were perceived to be more competent and less likable.

In Table 1, all four traits were statistically significant. Table 3 reveals that only two of the traits survive when we relate them to compensation through the numerical scoring of facial traits. Here neither trustworthiness nor attractiveness is significant. The

\footnotetext{
${ }^{6}$ Total compensation is comprised of the following other Execucomp entries: salary, bonus, other annual income, total value of restricted stock granted, total value of stock options granted (using Black-Scholes), long-term incentive payouts, and all other compensation.
} 
economics literature emphasizes the importance of a beauty premium. Consequently, we conduct further analysis that focuses on beauty and competence. We ask respondents to rank the CEOs just on competence and beauty on a scale of 1 to 5 . We have an additional 208 respondents who rank the CEOs. The key results from above still hold in this focused analysis (not reported in the tables). On this subsample too, competence is significantly correlated to company size but not so for attractiveness, with the numbers being very similar to that seen in Table 3.

What about the economic impact? In the experiments in Table 1 , this is difficult to measure since it is hard to put an economic interpretation on $54 \%$ of the respondents thinking the $\mathrm{CEO}$ is more competent. However, the numerical scoring allows us to measure the economic impact. Suppose that we move from a score of $3 / 5$ to $4 / 5$ in terms of competence. Using unreported results from univariate regressions (as opposed to the correlations reported in Table 3), we find that this translates into a $7.5 \%$ increase in total compensation for the CEO and a 12.5\% increase in firm sales. Meanwhile, increasing likeability from $3 / 5$ to $4 / 5$ reduces total compensation by $9.2 \%$ and sales by $13.9 \%$. In each case, this is an economically significant effect.

\section{Relative Pay Effects}

We next examine whether the pay of the CEO is affected by facial features. In particular we examine the CEO compensation as a function of facial features and controlling for previous CEO pay. We include size of the company and industry controls as these are known to be important determinants of CEO compensation. Another way to frame the question is whether the pay of the CEO relative to the previous CEO, after 
controlling for size of the company, and industry is affected by facial features. Table 4, panel A examines this in a regression framework. ${ }^{7}$ We find that of the facial features only “competent looks” is positively and significantly related to the CEO’s pay relative to the previous CEO after controlling for company size and industry controls. The other facial characteristics are insignificant in the regressions. These results hold when the facial traits are put in separately as well as simultaneously in the regression.

In terms of economic significance, the estimates from Table 4, panel A suggest that increasing the competence rating from $3 / 5$ to $4 / 5$ approximately translates into a 4.6$5.0 \%$ increase in total compensation for the CEO.

As we can see from Table 4, panel A, the number of observations decreases significantly in these regressions because there are many long-standing CEOs whose compensation we cannot benchmark against the prior CEO’s compensation. For such CEOs we create a proxy of the prior CEO's compensation by taking the median compensation of all CEOs in the same two digit SIC code. Table 4, panel B reports the results. The results for the full sample of CEOs is very similar to the results in Table 4, panel A. Competence is the only facial attribute that is statistically significant. In terms of economic significance, the estimates from Table 4, panel B suggest that increasing the competence rating from $3 / 5$ to $4 / 5$ approximately translates into a $4-5.1 \%$ increase in total compensation for the CEO.

\footnotetext{
7 In all we have 7,772 observations (which come from 138 CEOs being rated by 230 raters who, on average, rated 33 CEOs apiece). Standard errors are clustered at the CEO level. We also estimate a regression where we put a control for if the CEO was replaced more than five years ago. The control is insignificant and does not affect our main results.
} 


\section{Facial traits and performance}

The CEO search process is typically a long and complicated one. There is much data on past performance of a CEO and unlike votes in the political process here the decision is typically made by a handful of people who evaluate this decision carefully. Yet, our results suggest that competent looks matter for CEO selection and pay. There is ample evidence in the psychology literature that assessments based on facial appearance do not necessarily translate into corresponding behavior. Thus having the appearance of a facial trait does not mean one will actually display that trait. Hence the next question that arises is whether competent looking CEOs are actually more competent?

To assess this question we regress the ROA of the company on the facial traits of the CEO after controlling for size of the company, industry and the ROA under the prior CEO. The results are reported in Table 5. None of the facial traits are statistically significant and the point estimates are near zero. These results along with the results in Table 4 suggest that facial traits affect compensation but not performance. This result is consistent with the "beauty premium" literature which suggests that there is a wage premium for beauty but finds no evidence to suggest that this wage premium is justified in terms of performance. The difference is that in the corporate context, in the CEO labor market, it would appear that there is a "competent looks" premium as opposed to a beauty premium. Our results suggest the importance of expanding the work done regarding beauty wage premium by looking at facial attributes more broadly, particularly in the corporate sector. 


\section{E. Maturity and competence}

We next investigate the factors behind the importance of competent looks. We inquire whether the reason for competent looks or likeability is based on intrinsic "babyfaced” or "maturity" of facial attributes, as suggested by prior work. Our subjects evaluate the CEOs based on whether they appear baby-faced or mature. Prior work (e.g., Berry and McArthur, 1985) suggests that these traits are scientifically measurable as opposed to being subjective. As mentioned earlier, the task of classifying mature versus baby-faced is more analytic in nature and based on tangible facial traits. As such, we employed a small group of $10 \mathrm{Ph}$.D. students to do these ratings.

Table 6 presents the bivariate correlations between baby-faced and the four facial traits of competence, beauty, likeability, and trustworthiness. Interestingly, competence is negatively and significantly correlated with baby-facedness, with a correlation of $25.3 \%$, which is significant at a $1 \%$ level. Essentially, the subjects are classifying CEOs with mature-faced attributes as competent. Likeability is positively and significantly correlated with having baby-faced features (correlation of $24.1 \%$, significant at $1 \%$ ). This is consistent with our results. The more mature-looking CEOs are less likable. Neither attractiveness nor trustworthiness is significantly correlated with mature features. These results suggest that differences in the perception of competence (and likability) are significantly influenced by baby-faced appearances (versus appearing mature-faced).

\section{Conclusion}


Some remarkable research in political science shows that subjects can accurately identify the winner of a Congressional election simply by looking at the face of the candidate for a few seconds. Our research goal is to see if there is any relation between facial traits and rising to the job title of CEO. Our results, based upon a series of experiments involving close to 2,000 subjects, suggest there is a significant relation.

Our first experiment tests to see whether subjects evaluate the facial traits of CEOs to be different when showed a photograph of the CEO and a carefully matched non-CEO. We ask the subjects to select the one that looks the most "competent", "trustworthy", "likable", and "attractive". In this experiment, we find that CEOs are perceived to be more competent and slightly more attractive. The CEOs are considered less likable and less trustworthy.

Our second experiment tests whether subjects ascribe different facial characteristics to CEOs who run large versus small firms. This separation is important because we know that large firm CEOs earn much higher compensation. The strongest results are consistent with the first experiment. The large-firm CEOs are perceived to be more competent and less likable.

In addition, to picking among a pair of photos, the subjects numerically score the facial traits of CEOs. This allows us to directly examine whether these quantitative scores are related to executive compensation. Our results show a highly statistically significant relation between competence, likeability and executive compensation. When we control 
for the CEO's pay relative to prior CEO, after controlling for firm size and industry, we find that competence is significantly related to the CEO's pay. All other facial traits are insignificant.

Are competent looking CEOs actually more competent? We examine the performance of the firms run by CEOs to see if facial attributes are related to performance, by running regressions similar to the ones for CEO compensation. We find no evidence that competent looking CEOs demonstrate better firm performance.

Finally, we explore possible reasons for the subjects' perception of these four facial traits. Following the psychology literature, we quantitatively evaluate the "babyfacedness" of the CEOs. We find that the maturity of the facial appearance is significantly related to perceptions of competence and likeability. Our results are concerning particularly in the light of our findings that there is no relationship between competent looks of the CEO and firm performance. This also relates to the psychology literature which finds that people that are "baby-faced" are often more intelligent and possess other actual characteristics that are at odds to those projected by facial traits. In other words, baby-faced individuals may actually be more able, on average, than the rest of the population. Yet, our corporate beauty contest suggests that the "baby-faced" subjects are less likely to be CEOs and less likely to be large company CEOs. 


\section{References}

Bebchuck, L., and Y. Grinstein (2005). The growth of executive pay. Oxford Review of Economic Policy, 283-303.

Berry, D.S., and L. Z. McArthur (1985). Some components and consequences of a babyface. Journal of Personality and Social Psychology, 48(2), 312-323.

Biddle, J.E., and D.S. Hamermesh (1998). Beauty, productivity, and discrimination: Lawyers’ looks and lucre. Journal of Labor Economics, (16)1, 172-201.

Collins, M., and L.A. Zebrowitz, 1995. The contributions of appearance to occupational outcomes in civilian and military settings. Journal of Applied Social Psychology 25, 129163.

Duarte, J., S. Siegel, and L. Young (2009). Turst and Credit. Working paper, University of Washington, Seattle.

Hamermesh, D.S., and J. E. Biddle (1994). Beauty and the labor market. American Economic Review, 84(5), 1174-1194.

Mobius, M.M. and T.S. Rosenblat (2006). Why beauty matters. American Economic Review, 96(1), 222-235. 
Ravina, E. (2008), Love and loans: The effect of beauty and personal characteristics in credit markets, Working paper, New York University.

Rule, N. O., and N. Ambani (2008). The face of success. Psychological Science, 109111.

Todorov, A., A.N. Mandisodza, A. Goren, C.C. Hall (2005), Inferences of competence from faces predict election outcomes. Science, 308, 1623-1626

Zebrowitz, L.A., Andreoletti, C., Collins, M.A., Lee, S.Y., \& Blumenthal, J. (1998). Bright, bad, baby-faced boys: Appearance stereotypes do not always yield self-fulfilling prophecy effects. Journal of Personality and Social Psychology, 75, 1300-1320.

Zebrowitz, L.A., and J.M. Montepare (2005). Appearance DOES matter. Science, 308, 1565-1566.

Zebrowitz, L.A. (1997). Reading Faces: Window to the Soul? Boulder, CO: Westview Press. 
Figure 1

CEOs vs. Non-CEOs

Eircture Comparisons - Windows Intenet Explore

(3) - e http://www.duke-experiment.org/

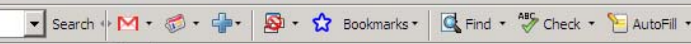

$7 \sqrt{4} \times \longdiv { \text { Google } }$

है the Picture Comparisons
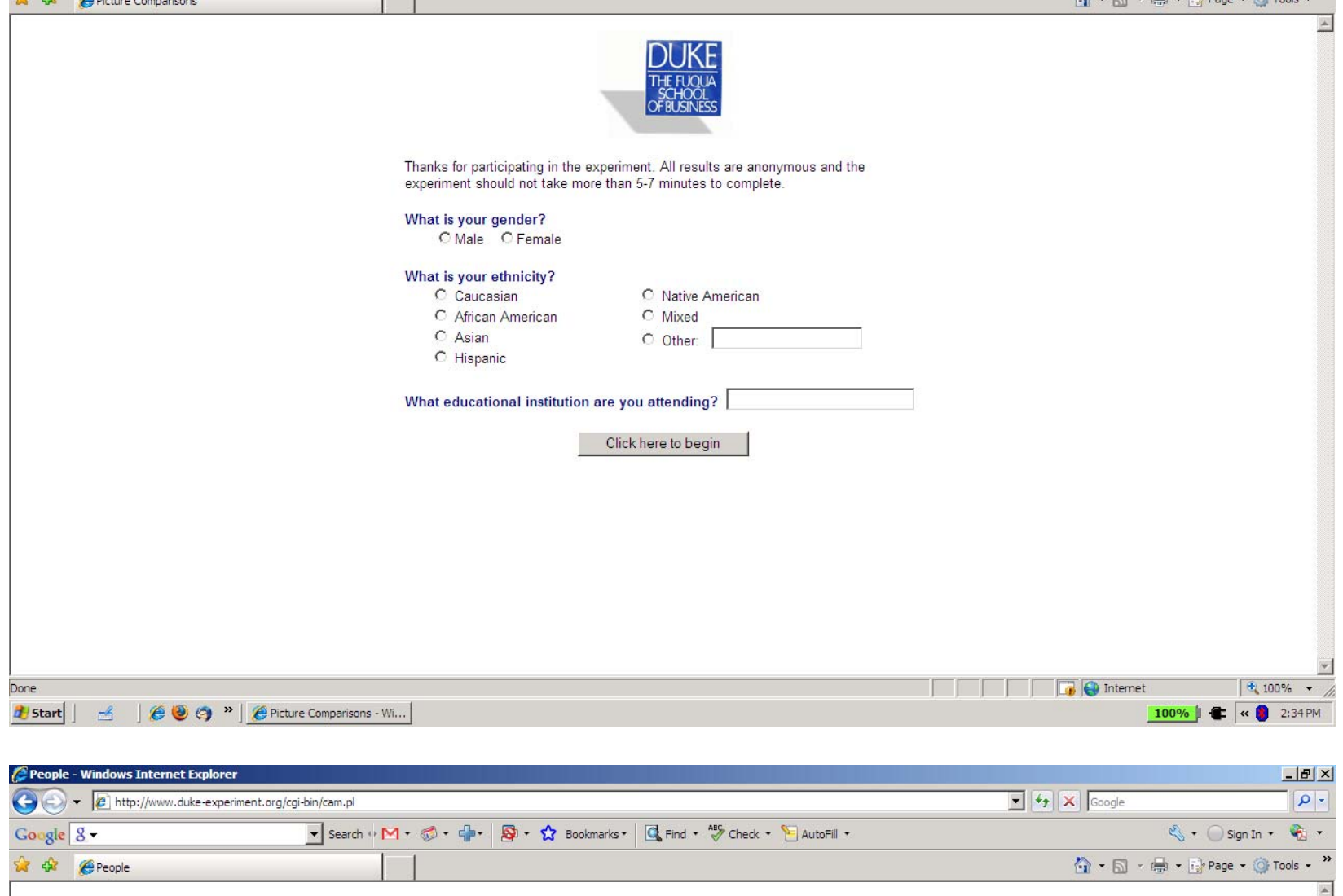

री दो tereople
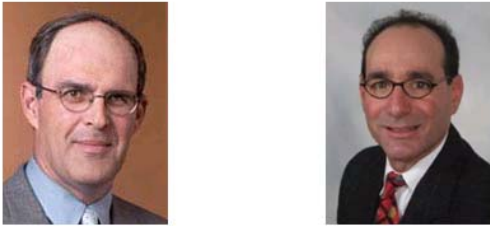

Which person is more

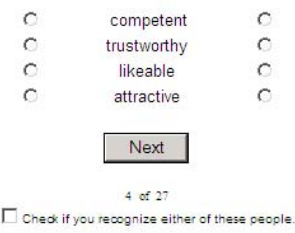

Done

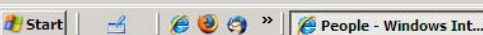

क, $100 \%$

$100 \%$ 2:52 PM 
Figure 2

\section{Large Company CEOs vs. Small Company CEOs}

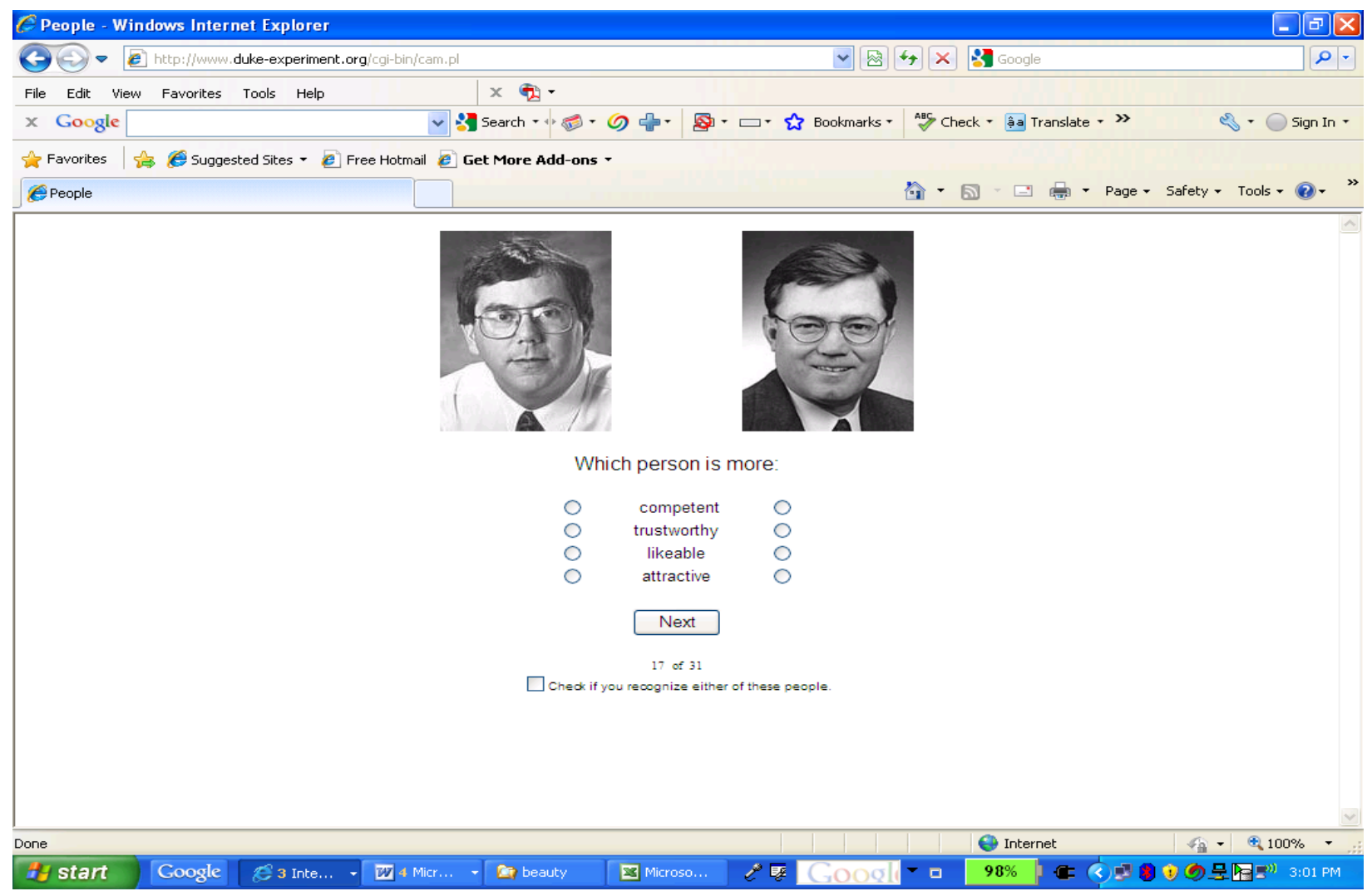


Figure 3

\section{Numerical scoring of the facial traits of CEOs}

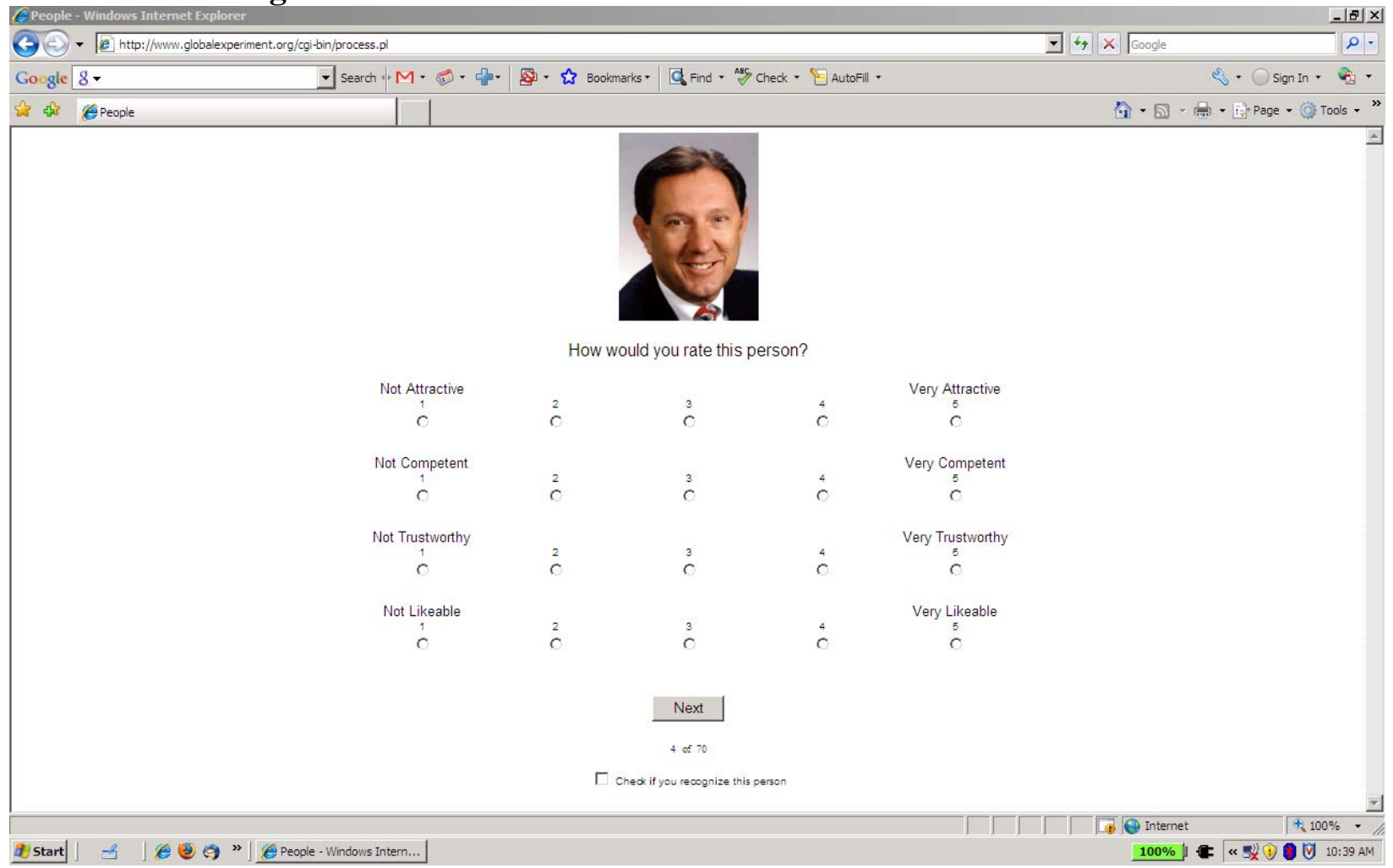




\section{Table 1}

\section{Pair-wise Comparison of Facial Traits of CEOs and non-CEOs}

CEO and non-CEO executives were matched into 87 pairs for evaluation by survey respondents. CEOs of large firms were also matched with CEOs of small firms to form 61 large firm/small firm pairs. Panel A reports the percentage of survey respondents who selected the CEO member of a CEO/non-CEO pair as more competent, trustworthy, likable, or attractive. Panel B reports the percentage of survey respondents who selected the large firm CEO member of a large firm/small firm pair as more competent, trustworthy, likable, or attractive. Observation weighted averages represent the percentage of all respondent-pair observations for which the CEO (large firm CEO) was picked. The straight average calculates the percentage of the time the CEO (large firm CEO) was picked for each pair and reports the mean of these pair averages. Z-statistics test the null hypothesis that the probability of picking the CEO (large firm CEO) is $50 \%$ and are reported below point estimates. Single, double, and triple asterisks denote significance at the $10 \%, 5 \%$ and $1 \%$ level, respectively.

Panel A

\% Correctly Choosing the CEO

Observation weighted average (\%)

\begin{tabular}{rrrr} 
Competent & Trustworthy & \multicolumn{1}{c}{ Likable } & Attractive \\
\hline $53.800^{* * *}$ & $47.956^{* * *}$ & $49.281^{*}$ & $51.378^{* * *}$ \\
8.830 & -4.751 & -1.670 & 3.202 \\
$54.126 * * *$ & $47.953^{* * *}$ & $48.769 * * *$ & $51.539 * * *$ \\
9.429 & -4.676 & -2.812 & 3.516
\end{tabular}

Number of pairs

87

$$
87
$$

765

87
765

87

765

87

Number of respondents

\% Correctly Choosing the Large Firm CEO

Panel B

\begin{tabular}{rrrr} 
Competent & Trustworthy & \multicolumn{1}{c}{ Likable } & Attractive \\
\hline $54.563^{* * *}$ & $48.449 * * *$ & $43.873^{* * *}$ & $46.293^{* * *}$ \\
10.942 & -3.720 & -14.695 & -8.890 \\
$54.484 * * *$ & $48.671^{* * *}$ & $44.453^{* * *}$ & $46.519 * * *$ \\
10.641 & -3.154 & -13.162 & -8.260
\end{tabular}

Number of pairs

61

Number of respondents

762

61
762

61
762

61

762 
Table 2

Correlation Matrix for Facial Traits of CEOs

138 CEOs were rated on a scale of 1 to 5 with respect to whether they looked competent, trustworthy, likable, and attractive. The correlation matrix of CEOs' average rating on these traits is reported. P-values are reported below correlations. Single, double, and triple asterisks denote significance at the $10 \%, 5 \%$ and $1 \%$ level, respectively.

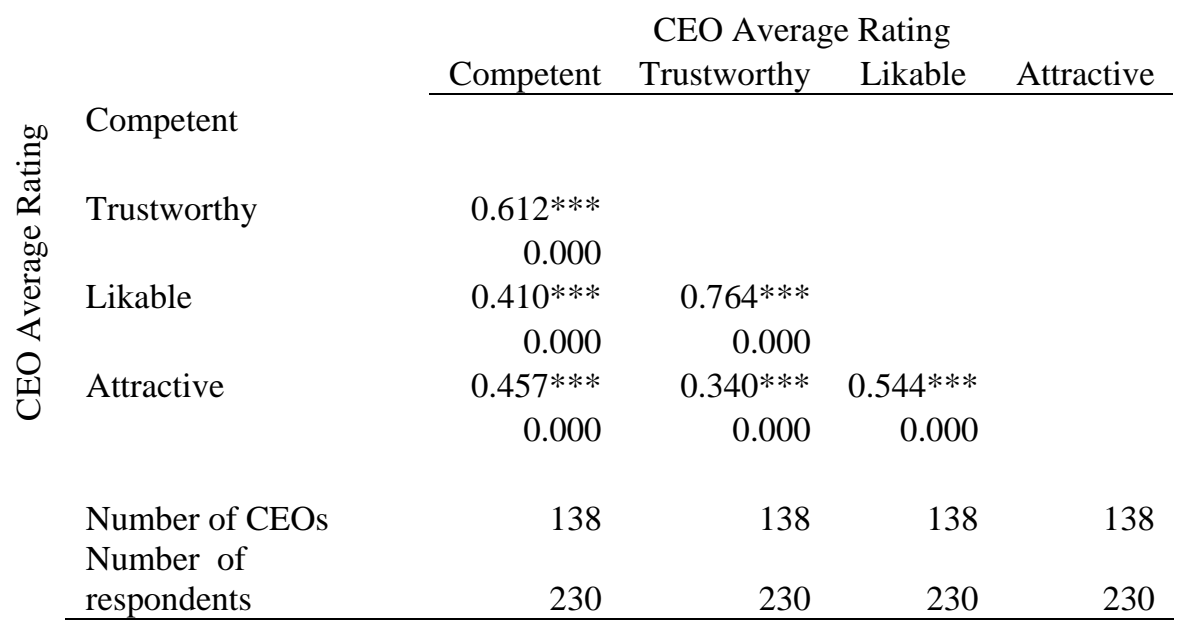


Table 3

\section{CEO traits, Company Size and Income}

Respondents rated CEOs on a scale of 1 to 5 with respect to competence, trustworthiness, likability, and attractiveness. Univariate correlations between these ratings and the total sales of the CEO's firm, and CEO income are reported. $\ln ($ Sales) was calculated as the log of the firm's sales ("Net Sales" in Execucomp) for fiscal year 2003. In(Income) was calculated as the log of CEO income ("TDC1" in Execucomp) for fiscal year 2003. For firms missing income or sales information in 2003, information from 2004 or 2005 was used. P-values are reported below correlations and are adjusted for clustering at the CEO level. Single, double, and triple asterisks denote significance at the $10 \%, 5 \%$ and $1 \%$ level, respectively.

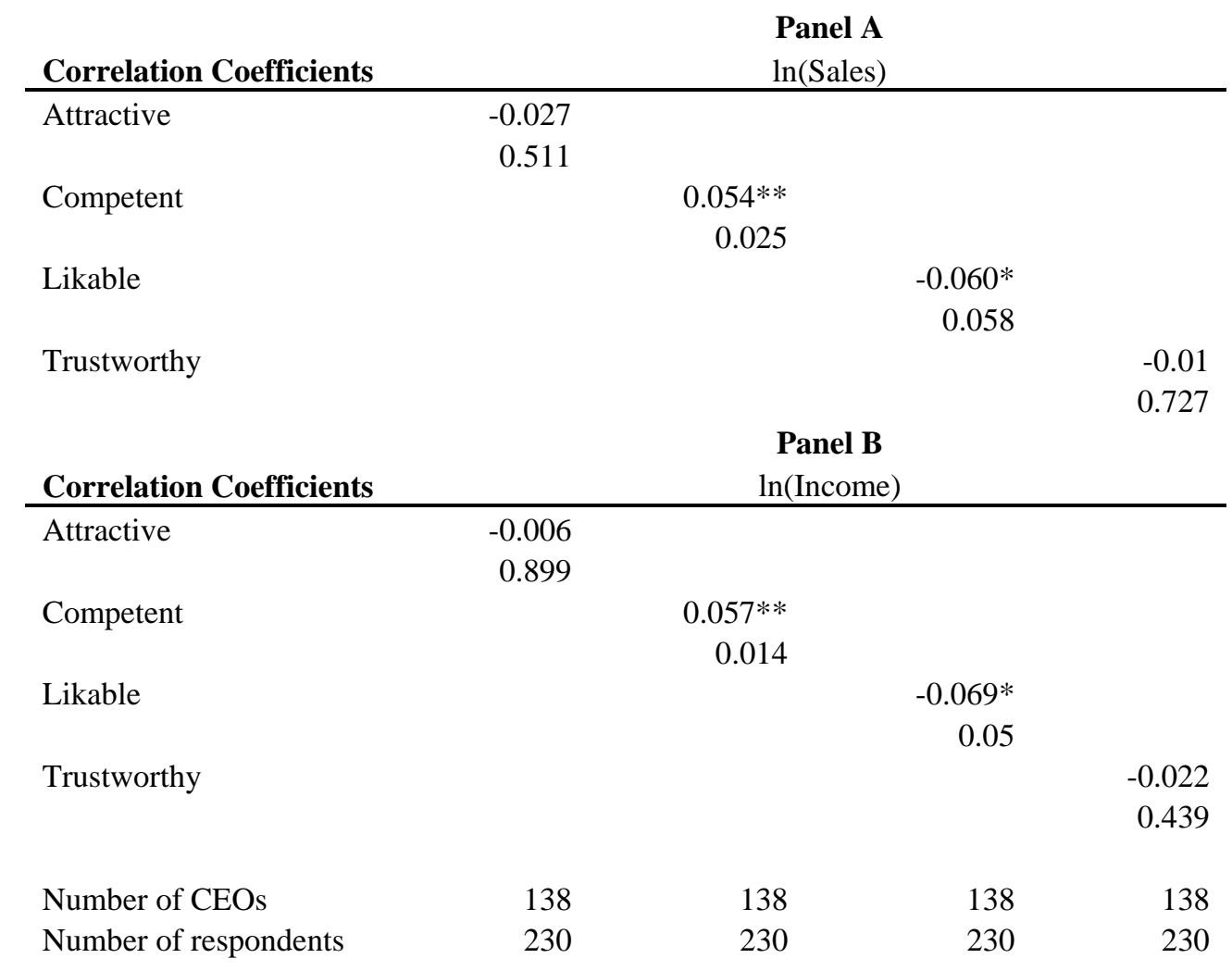


Table 4

\section{CEO Traits and Income}

Regressions of the log of CEO income on facial traits and controls are reported. $\ln ($ Sales) was calculated as the log of the firm's sales ("Net Sales" in Execucomp) and ln(Income) was calculated as the log of CEO income ("TDC1" in Execucomp) for fiscal year 2003. For firms missing incomes or sales information in 2003, information from 2004 or 2005 was used. All regressions also include 1-digit SIC industry dummies. Finally, we control for the income of the company's prior CEO for the year before the rated CEO was hired. For several CEOs, no information is available on the prior CEO's income. In panel B, we replace these missing values with the average income paid to CEOs in the same 2-digit SIC industry in 2003. Standard errors are reported below coefficients and are clustered at the CEO level. Single, double, and triple asterisks denote significance at the $10 \%, 5 \%$ and $1 \%$ level, respectively.

\begin{tabular}{|c|c|c|c|c|c|}
\hline \multirow{2}{*}{$\frac{\text { Panel A }}{\text { Attractive }}$} & \multicolumn{5}{|c|}{$\ln$ (Income) } \\
\hline & $\begin{array}{l}0.009 \\
(0.046)\end{array}$ & & & & $\begin{array}{l}0.004 \\
(0.047)\end{array}$ \\
\hline Competent & & $\begin{array}{l}0.046^{*} \\
(0.027)\end{array}$ & & & $\begin{array}{l}0.050^{*} \\
(0.027)\end{array}$ \\
\hline Likable & & & $\begin{array}{l}-0.004 \\
(0.031)\end{array}$ & & $\begin{array}{l}-0.040 \\
(0.033)\end{array}$ \\
\hline Trustworthy & & & & $\begin{array}{l}0.024 \\
(0.026)\end{array}$ & $\begin{array}{l}0.023 \\
(0.024)\end{array}$ \\
\hline ln(PriorCEO Income) & $\begin{array}{l}0.150 * * \\
(0.069)\end{array}$ & $\begin{array}{l}0.152^{* *} \\
(0.069)\end{array}$ & $\begin{array}{l}0.150 * * \\
(0.069)\end{array}$ & $\begin{array}{l}0.151^{* *} \\
(0.069)\end{array}$ & $\begin{array}{l}0.151^{* *} \\
(0.068)\end{array}$ \\
\hline $\ln$ (sales) & $\begin{array}{l}0.350 * * * \\
(0.055)\end{array}$ & $\begin{array}{l}0.348^{* * * *} \\
(0.055)\end{array}$ & $\begin{array}{l}0.349 * * * \\
(0.055)\end{array}$ & $\begin{array}{l}0.349 * * * \\
(0.055)\end{array}$ & $\begin{array}{l}0.348^{* * *} \\
(0.055)\end{array}$ \\
\hline Industry dummies & YES & YES & YES & YES & YES \\
\hline R-squared & 0.578 & 0.579 & 0.578 & 0.578 & 0.579 \\
\hline Number of observations & 4061 & 4061 & 4061 & 4061 & 4061 \\
\hline Number of CEOs & 71 & 71 & 71 & 71 & 71 \\
\hline Number of respondents & 227 & 227 & 227 & 227 & 227 \\
\hline Panel B & & & $\ln$ (Income & & \\
\hline Attractive & $\begin{array}{l}0.023 \\
(0.040)\end{array}$ & & & & $\begin{array}{l}0.024 \\
(0.041)\end{array}$ \\
\hline Competent & & $\begin{array}{l}0.040^{*} \\
(0.021)\end{array}$ & & & $\begin{array}{l}0.051^{* *} \\
(0.024)\end{array}$ \\
\hline Likable & & & $\begin{array}{l}-0.012 \\
(0.031)\end{array}$ & & $\begin{array}{l}-0.041 \\
(0.035)\end{array}$ \\
\hline Trustworthy & & & & $\begin{array}{l}0.004 \\
(0.022)\end{array}$ & $\begin{array}{l}-0.003 \\
(0.022)\end{array}$ \\
\hline ln(PriorCEO Income) & $\begin{array}{l}0.213 * * * \\
(0.061)\end{array}$ & $\begin{array}{l}0.214 * * * \\
(0.061)\end{array}$ & $\begin{array}{l}0.212 * * * \\
(0.061)\end{array}$ & $\begin{array}{l}0.213^{* * * *} \\
(0.061)\end{array}$ & $\begin{array}{l}0.212^{* * * *} \\
(0.061)\end{array}$ \\
\hline $\ln$ (sales) & $\begin{array}{l}0.347^{* * *} \\
(0.042)\end{array}$ & $\begin{array}{l}0.346^{* * * *} \\
(0.042)\end{array}$ & $\begin{array}{l}0.347^{* * * *} \\
(0.042)\end{array}$ & $\begin{array}{l}0.347 * * * \\
(0.042)\end{array}$ & $\begin{array}{l}0.345^{* * *} \\
(0.042)\end{array}$ \\
\hline Industry dummies & YES & YES & YES & YES & YES \\
\hline R-squared & 0.484 & 0.484 & 0.483 & 0.483 & 0.485 \\
\hline Number of observations & 7772 & 7772 & 7772 & 7772 & 7772 \\
\hline Number of CEOs & 138 & 138 & 138 & 138 & 138 \\
\hline Number of respondents & 230 & 230 & 230 & 230 & 230 \\
\hline
\end{tabular}


Table 5

\section{CEO Traits and Performance}

Regressions of the return on assets of rated CEOs on facial traits and controls are reported. ROA is calculated as net income divided by total assets (NI/AT in Compustat) and $\ln$ (Sales) was calculated as the log of the firm's sales ("Net Sales" in Execucomp) for fiscal year 2003. For firms missing ROA or sales information in 2003, information from 2004 or 2005 was used. All regressions also include 1-digit SIC industry dummies. Finally, we control for the ROA earned by the company's prior CEO in the year before the rated CEO was hired. Standard errors are reported below coefficients and are clustered at the CEO level. Single, double, and triple asterisks denote significance at the $10 \%, 5 \%$ and $1 \%$ level, respectively.

ROA

\begin{tabular}{llllll}
\hline Attractive & $\begin{array}{l}-0.001 \\
(0.004)\end{array}$ & & & & -0.002 \\
Competent & & 0.003 & & & $(0.004)$ \\
& & $(0.002)$ & & & 0.003 \\
Likable & & & 0.002 & & $(0.003)$ \\
& & & $(0.004)$ & & 0.003 \\
Trustworthy & & & 0.001 & $(0.004)$ \\
& & & & $(0.003)$ & $(0.002$ \\
Prior CEO ROA & 0.093 & 0.094 & 0.093 & 0.093 & 0.093 \\
& $(0.099)$ & $(0.100)$ & $(0.100)$ & $(0.100)$ & $(0.100)$ \\
ln(sales) & $0.011^{* *}$ & $0.011^{* *}$ & $0.011^{* *}$ & $0.011^{* *}$ & $0.011^{* *}$ \\
& $(0.005)$ & $(0.005)$ & $(0.005)$ & $(0.005)$ & $(0.005)$ \\
Industry dummies & & & & & \\
R-squared & YES & YES & YES & YES & YES \\
Number of observations & 5389 & 0.189 & 0.189 & 0.188 & 0.190 \\
Number of CEOs & 95 & 5389 & 5389 & 5389 & 5389 \\
Number of respondents & 230 & 95 & 95 & 95 & 95 \\
& 230 & 230 & 230 & 230
\end{tabular}




\section{Table 6}

\section{Baby-Faced and Other Facial Traits}

138 CEOs were rated 1 to 5 on being "baby-faced", 5 being the most "baby-faced". The correlation of CEOs' average baby-faced rating with their average competence, trustworthiness, likability, and attractiveness are reported. P-values are reported below correlations. Single, double, and triple asterisks denote significance at the $10 \%, 5 \%$ and $1 \%$ level, respectively.

Baby-faced

Competent
$-0.253^{* * *}$
0.003

Number of CEOs

Number of respondents

230
CEO Average Rating

$\begin{array}{ccc}\text { Trustworthy } & \text { Likable } & \text { Attractive } \\ 0.027 & 0.241^{* * *} & 0.028 \\ 0.756 & 0.004 & 0.743\end{array}$

138

138

138

230

230

230 